\title{
Caderneta de lembranças
}

\author{
LUIZ SÁVIO DE ALMEIDA
}

$\mathrm{N}$ ão gOSTO MUito da palavra memória; prefiro lembrança, coisa bem mais simples, ligada ao comum do dia a dia. Todo mundo tem lembrança; raros os que dizem memória. É assim que me lembro da viagem, saindo do Colégio XV de Novembro em Garanhuns no qual era interno e rumando para Natal, rua Felipe Camarão, local em que meus pais estavam morando, após termos vivido em Palmares, mata pernambucana por onde passa o Rio Una, sujo e fedorento de tiborna da Usina. Meu pai era andejo: funcionário do Banco do Brasil. Nossa vida sempre foi uma permanente mudança: a gente nunca tomava banho duas vezes no mesmo rio, embora não houvesse rio apenas em uma cidade em que moramos: Bicas, cheia de café nas Minas Gerais, quase um bairro de Juiz de Fora.

Rebolei na estrada, cheguei novamente sem amizades. Tratei da matrícula no Marista: terceiro ano de Colégio e no ponto de fazer vestibular. De leitura, na realidade, havia decorado $O$ que sabe você sobre o Petróleo somente para atentar a alma dos missionários norte-americanos que ensinavam no XV de Novembro: presbiteriano. Passei filando em matemática; havia um gênio, Quincas. Ele resolvia os problemas em um talão de jogo de bicho e distribuía as folhas. Então, terminei o colegial, com quadro de formatura e tudo mais. Fazer vestibular... Danei-me a estudar para Medicina mas desisti, faltando três meses para a prova. Fui fazer Direito: decorei Cícero e Ovídio na ordem direta e na indireta e passei.

Foi nessa oportunidade, que fiz amizade com um cara chamado Marcos Guerra; era de uma família muito ligada à Igreja. Eu vivia da mesada de meu pai. A Emissora de Educação Rural-pertencia à Arquidiocese - abriu um curso para locutor e fui fazer. Levei cacete na locução esportiva; não tinha velocidade para acompanhar a bola; era um desastre. Marcos Guerra conseguiu um emprego para mim na Caritas Diocesana e, então, começou a minha vinculação mais direta com a Igreja de Natal. Apesar da grande amizade que nos uniu, o gringo jamais andou satisfeito com o meu trabalho e isso com toda a razão. Por outro lado, eu não conseguia ficar datilografando e Michael deve ter pensado em me despedir, mas não tinha como burlar a amizade. 
Vai que apareceu uma oportunidade: ir trabalhar no Serviço de Assistência Rural, uma ONG (como se diria hoje) ligada à Arquidiocese e dirigida por D. Eugênio de Araújo Salles que era - parece-me - bispo auxiliar. É isso mesmo: D. Marcolino ainda estava vivo, morando numa casa lá perto da Catedral. Meu trabalho foi no Setor de Sindicalização do SAR, nome um tanto quanto pomposo para uma pequena sala, um ventilador, um arquivo de aço e duas pequenas mesas. Depois, fui trabalhar no Movimento de Educação de Base, que operava com a rede de escolas radiofônicas montada pela Arquidiocese. Pouco a pouco, as responsabilidades cresceram e, vez em quando, viajava para um ou outro lugar, em função de encontros ou algum tipo qualquer de assessoria até mesmo em outra Diocese. Era coisa de homem feito, posta em cima de menino, a demonstrar quanto a política daquele período pressionou a nossa geração, obrigando a que se construísse, urgentemente, toda uma ordem de experiência.

Duas palavras andaram em jogo nesse tempo. A primeira era politização e teve imenso prestígio; depois é que entra conscientização. Elas deram o compasso às discussões internas sobre educação. Não sei se tenho razão, mas educação de base, politização e conscientização indicam tempos no movimento, com a última revelando, inclusive, a crescente importância de Paulo Freire a partir de sua experiência no Recife. Foram momentos rápidos e sutis, mas tive a oportunidade de vivê-los. Dar nome aos tempos, parece eqüivaler a um esforço de colocar a vida em prateleiras mas, se por um lado pega mal, ajuda a organizar as lembranças.

Pois bem, a minha entrada no SAR levou-me a uma convivência de perto com a Juventude Universitária Católica e com os primórdios da Ação Popular que nasceu visceralmente ligada à JUC. Os quadros iniciais da AP no Rio Grande do Norte, por exemplo, eram basicamente JUC. Eram de grande peso uma revista publicada em Minas Gerais (se não me engano, coordenada pelo Betinho), um livro publicado pela UNE e que parece se intitulava Cristianismo hoje, além de um filósofo jesuíta chamado Henrique de Lima Vaz que trabalhava dois temas básicos: consciência histórica e, por extensão, o engajamento cristão.

Para a JUC, dentre outros pontos, a AP significava liberdade para agir, pois como organização do laicato mantinha vínculos com a autoridade episcopal e se estrangulava politicamente, à medida em que avançava proposições e alianças indo até os comunistas, velhos fantasmas para a hierarquia. Lembro-me, que certa feita, quando se discutia o local para um encontro nacional, a opção foi Aracaju e isso significa que D. Távora, 
apesar dos pesares, era uma das poucas portas. Foi nesse encontro em Sergipe que conheci o padre Vaz, pessoa erudita e amável, com quem cheguei a manter correspondência, pedindo orientação para leituras.

Era Natal, o que se poderia considerar como pólo das atividades sociais da Igreja no Nordeste. Isso, apesar de o bispo ser conservador, mas trabalhava em face de sua percepção da Doutrina Social da Igreja: uma terceira via que poderia ter desvios à direita, mas jamais à esquerda, justamente, pelo perigo de encontrar-se com o comunismo. Recentemente, ao examinar uma dissertação, é que entendi a profundidade da construção anticomunista pela hierarquia católica. Esse homem teve uma extraordinária influência em minha vida e ainda dedico-lhe, apesar do afastamento, um grande carinho. Não posso negar que parte do meu modo de ser foi forjado em nossa convivência. Foi uma convivência de conflitos, em razão de posições políticas, mas isso jamais abalou as relações pessoais. Minha cabeça é muito devedora da obstinação, da dedicação que aprendi ao trabalhar com ele.

Teoricamente, a minha cabeça era a mais perfeita e brutal confusão. Lia e relia os textos da Doutrina Social da Igreja; saía de Martitain, entrava por Chardin, investia em Mounier, mas tinha um namoro furtivo com Marx que aumentava na medida que me relacionava com a AP. Lia o ISEB como se estivesse diante da mais potente demonstração da inteligência. Brigava com os comunistas, somava com eles, estudava direito e, pouco a pouco, no meio de toda a confusão, foram aumentando as minhas responsabilidades no SAR.

Houve uma eleição para o Diretório Central dos Estudantes. Não me lembro se entrei na chapa; somente sei que o candidato a presidente era o Ginani (hoje médico em Brasília) e que fiquei como diretor de Cultura. Conversamos, arranjaram passagem e fui para o Recife com a missão de marcar a ida de Paulo Freyre a Natal. A chapa eleita havia sido uma composição entre JUC (nem todos de JUC eram de AP), AP, PCB e os que eram considerados independentes.

A antiga Reitoria da UFPE era no parque Treze de Maio (será esse o nome?). Eu tinha alguns assuntos pessoais a resolver: fui saber se poderia me inscrever para o concurso do Instituto Rio Branco; disseram que não tinha idade. Fui procurar inscrever-me em algum daqueles cursos (conhecidos na época como cursinhos Wallita) da Sudene: também disseram que eu não tinha idade. Devidamente esclarecido de que deveria ficar velho, fui procurar o Paulo Freire no Departamento de Extensão Cultural. 
Fui muito bem recebido e acertamos a sua ida; mais ou menos meiodia, deu-me uma carona, num fusca velho. Lembro do papo no caminho. Ele me disse que tudo havia começado a partir de um filho seu e da televisão. $\mathrm{O}$ menino passava com ele por uma rua, viu uma propaganda e gritou: "Olha papai, Nescau!" Disse o Paulo Freire que se convenceu da força da imagem. Hoje em dia, acredito que existiram, pelo menos, três Paulos. Um primeiro ainda preocupado com problemas tipo economia da educação; o segundo à procura de caminho e, finalmente, o Paulo Freire depois de 1964, quando entra em maturidade, gerando a obra que se registrou na educação internacional. Nessa época em que procurei manter o contato, eu ainda trabalhava no Serviço Assistência Rural com D. Eugênio.

Em determinada época, tivemos um problema sério, pois eu havia sido convidado - e aceitei - para falar em um Congresso Nacional de Trabalhadores Rurais. A Diocese era contra. O argumento de D. Eugênio era que eu fazia parte de uma equipe e somente poderia falar o que o grupo pensava. De certa forma ele tinha razão, pois o que eu dissesse seria implicado com o trabalho. Insisti, que o convite era pessoal e terminamos por concordar que eu deixaria de trabalhar com ele, tudo numa boa. Mas, acredito, ele estava altamente preocupado, pois eu conhecia, como a palma de minha mão, grande parte das malhas da Igreja no Rio Grande do Norte.

O discurso que pronunciei foi altamente inflamado. Falava da força da história, da revolução que deveria ser feita, da importância da ligação entre operários e camponeses e estudantes na condução da revolução brasileira. Todo o lugar comum apareceu e a vitória sempre esteve falando alto. Aquilo era a febre da vitória, algo insofismável, automático, quase dois e dois são quatro, no modo de somar fatores políticos, de ver o futuro e de lançar a burguesia no caos de seu próprio enxofre. Pintei e bordei e cheguei a ser veladamente ameaçado de morte por um deputado federal que foi bisbilhotar o Congresso: "Se fosse na minha terra, eu dava um jeito em você!"

Não posso dizer que o trabalho de sindicalização rural somente havia sido realizado no Rio Grande do Norte, em face da contenção do avanço das Ligas Camponesas. Isso eqüivaleria a uma redução imensa do quadro político, mas havia, sem dúvida alguma, o componente contra elas. As Ligas Camponesas não deixavam de ser uma preocupação direta da Igreja. Estava sendo vivenciado um tempo em que o Nordeste foi transformado em barril de pólvora. A organização rural pelos comunistas 
no Rio Grande do Norte jamais foi forte. Isso não se deve, tão somente, à incapacidade que o Partido tinha em deixar de ser urbano; somavam-se a ela, sobretudo, as dificuldades de nucleação do trabalhador rural e, ainda, o avanço que a Igreja havia tido por meio das escolas radiofônicas do Movimento de Educação de Base e de seu prestígio secular na sociedade brasileira.

Pelo que entendo, essa sindicalização rural tinha dois matizes: antiliga e continuidade a longo prazo do trabalho social da Igreja. Eu não concordava com o antiliga; achava que ocupava um espaço que os sindicatos não podiam ocupar e que ambos eram necessários. Mas jamais tive qualquer aproximação com elas, mesmo pelo fato de que não chegaram sequer à fronteira do Rio Grande do Norte com a Paraíba. Somente fui fazer uma reportagem no caso de Sapé e no da Usina Estreliana: Paraíba e Pernambuco, respectivamente.

A Emissora de Educação Rural era a mola mestra de todo o trabalho da Arquidiocese. Não havia qualquer outra ligação de massa e politicamente organizada dentro da estrutura da Igreja. A Arquidiocese dispunha de um jornal de pouca penetração $(A$ Ordem $)$ e da emissora; em torno de $1 / 3$ de sua programação era centrada no meio rural, pois além das aulas, as escolas funcionavam como nucleação local, mediante monitores, e a audiência era cativa. Foi dessa rede que nasceu a liderançachave da sindicalização rural e, portanto, ela não deixava de ter um tom paroquial, elemento que D. Eugênio sempre cultivou. Talvez, daí, as reuniões freqüentes com o clero e dentre uma imensidão de pontos, o trabalho do Serviço de Assistência Rural paroquiava-se coordenadamente em todo o território da Diocese de Natal.

Sempre achei que D. Eugênio era o vigário de Acari, por onde, penso, começou sua vida sacerdotal. Daí, a Diocese era a paróquia, da qual ele era vigário e da qual gostava de ver tudo organizado: livro de tombo escrito direitinho, Matriz limpa, capelas sólidas e, à sua maneira, intrincada no cotidiano para o qual havia uma ordenação: Doutrina Social da Igreja. Era um vigário lido, mas sobretudo executivo, dando um forte acento à disciplina. O próprio carro chefe da Diocese tinha essa marca e era rural. A pergunta não é tola: qual a razão de não ser Serviço de Assistência Urbana? Era o vigário pensando no desenvolvimento, recebendo a herança do Serviço Social Rural, dos Clubes 4-S e por aí vai.

Caso a lembrança não seja troncha, a Igreja incorporara a sindicalização rural no Rio Grande do Norte, por meio da experiência de um setor específico que funcionava no Serviço Social da Indústria. Quando 
começou a operacionalizar a programação, encontrou o lastro plantado pela rede de escolas radiofônicas espalhadas. Depois, esse modelo foi sendo exportado para outras dioceses. Foi nessa sindicalização rural que começei a trabalhar, tendo passado antes pelo escritório da Caritas, onde minha função era apenas burocrática e tão escandalosamente desempenhada, que sempre senti a possibilidade de perder o emprego a cada minuto.

É claro que essa Igreja não poderia ser homogênea; havia conflito de toda a ordem, destacando-se a JUC. Era o que havia de mais avançado dentro da Ação Católica, o que se devia, talvez, à exposição de todos na vida universitária, densa de discussão e conflito que caracterizavam aquelas quadras de vida nordestina. Dentro do próprio Serviço de Assistência Rural existiam grupos e era extremamente difícil não haver choque. $\mathrm{O}$ que era escrito era facilmente controlável e, então, o que saia pela rádio também; mas era impossível controlar o que se dizia lá no campo, nas fazendas, nas casas de candeeiro aceso. Daí, alguns autores que estudaram o Serviço de Assistência Rural chegarem à conclusão de uma confusão teórica e de maior nível de coerência na ação. Quando o documento se destinava a algum encontro meio perigoso tinha que se pagar o preço de querer fazer o "batismo de Marx" - como diz um professor daqui da UFAL - na Sé da Doutrina Social da Igreja.

Acho que o grande problema político de D. Eugênio poderia ser personificado em Djalma Maranhão, irmão de Luiz Inácio Maranhão Filho, figura de destaque no PCB. Ele havia sido eleito para a Prefeitura de Natal e passou a desenvolver um trabalho de educação que mexia com a Igreja, face ao volume de massa que tomava: de pé no chão também se aprende a ler, com o qual colaborei de modo muito acidental e discreto. Apenas lembro que dei umas duas aulas em um treinamento.

Era um trabalho importante de inovação e dirigido pelo Moacir de Góes, migrante depois para o Rio de Janeiro, onde esteve, posteriormente, com o PSB. Um dos dirigentes desse trabalho era meu amigo íntimo; figura ainda muito querida - o mencionado Josemar - que me parece tinha ligações próximas ao PCB. Soube que eu havia deixado a Arquidiocese e me fez uma proposta: Djalma estaria interessado em entrar com ações no meio rural. Não sei se ele politicamente inventou e nem sei se realmente o recado teria vindo da Prefeitura: o fato é que eu disse não e a negativa circulou, não sei como, na certa devo ter comentado com outras pessoas.

Realmente, aceitar o convite seria uma brutal traição. D. Eugênio mandou alguém me telefonar marcando um encontro: ele realizou-se 
numa sala em que recebia visitas. Começou a falar e a falar e depois me agradeceu. Aí, foi outro problema, pois eu perguntei a ele se podia passar por sua cabeça que eu me comportaria como traidor. Depois de ter recebido tanta confiança, entregar ou ameaçar os esquemas seria moralmente trágico. Aliás, a proposta que D. Eugênio fez era singular: continuar trabalhando na Arquidiocese, mas sem nenhum contato com o público. Sabidamente, esteve querendo uma forma de me guardar. Eu disse que não se preocupasse; estava sendo dada minha palavra de que em nada comprometeria a Diocese. Disse, também, que havia aceito convite e iria trabalhar no grupo do Paulo Freire.

Jamais os desencontros perturbaram a minha amizade; eu gostava do cara e ainda hoje gosto. Podia não concordar com ele, mas era gente muito fina comigo. Outros podem pensar diferente, mas, como dizia a Madre Superiora, experiência pessoal é intransferível. Terminado esse encontro, durante o qual ele mandou servir formalmente um cafezinho, a amizade prosseguiu e, quase todo fim de semana, eu ia para a praia de Ponta Negra onde ficava o Centro de Treinamento da Diocese. Dormia em um quarto em frente ao seu. Vez em quando, eu pegava uma rede e roncava na varanda. Certa feita, após o boa noite de fim de jantar, nos encontramos por acaso. Ele me disse que havia sido convidado para a Bahia. Raramente nos vimos, desde quando ele foi para a Bahia, quando o vigário de Acari tornou-se cardeal.

A ida de Paulo Freire a Natal havia empolgado uma parte dos estudantes ligados direta ou indiretamente à esquerda. $\mathrm{O}$ auditório encheu e muitos estavam dispostos ao trabalho. Desconheço como foi feito um acordo, mas, tempos depois, um estudante ligado à AP me procurou dizendo ter sido convidado para a implantação do método Paulo Freire no Rio Grande do Norte. Aluísio Alves e seu secretário de Educação, Calazans Fernandes, jornalista que, segundo circulava, tinha ligações ou havia trabalhado com o grupo Times-Life, puxavam o trem. Havia sido realizado um acordo entre Sudene, governo do estado e Usaid para que fosse trabalhada a educação no estado. Nada sei como esse conchavão foi montado, mas bem que gostaria de sabê-lo.

Calazans Fernandes era insinuante, hábil. Aluísio Alves vinha de uma vitória sobre Dinarte Mariz. Corria que fizeram - Aluísio e Calazans - um projeto: vender o Rio Grande do Norte aos norte-americanos, mostrando que a miséria era recuperável dentro do barril de pólvora. Cuba deveria estar fumegando por aí. Nunca tive o menor contato com Aluísio e nem maiores aproximações com o Calazans Fernandes, apesar de achá-lo 
simpático, agradável, boa prosa. Faz tempo que não vejo Calazans; a última vez, estava dirigindo um projeto na Editora Abril. Realmente não sei como tudo se processou. Sei apenas que foi criada uma estrutura paralela à Secretaria de Educação e, dentro dela, começou a funcionar o pessoal do método.

O amigo que me havia procurado era Marcos Guerra e, caso eu lembre direitinho, era presidente da UEE. Conversamos, e acredito que foi em sua casa onde quase todas as noite estudávamos até tarde da noite. Discutimos as dificuldades e as perdas políticas que a montagem de uma equipe para a implantação do método geraria. Tratava-se de uma operação que, diziam, era financiada pela Usaid e os ecos do CPC da UNE eram fortes: o imperialismo. Ainda hoje não percebo quais foram as razões de a Usaid ter entrado na parada; na certa, não faria de bobeira; possivelmente, seus maiores investimentos estavam no Nordeste onde, quem sabe, o imaginário norte-americano da era Kennedy pensava a possibilidade de uma nova Cuba sem a Sierra Maestra mas com o açúcar.

A idéia da mobilização popular que poderia ser feita era fantástica; pensei que valeria comprar qualquer problema e não era uma oportunidade a ser perdida. Acho que o Marcos pensava o mesmo. Disse-lhe que trabalharia com ele e não participei da experiência pioneira de Angicos (terra de Aluísio Alves), mas, depois da saída da Diocese, entrei a todo o vapor. Depois de Angicos, o trabalho ganhou campo e, realmente, estourou a alfabetização em diversos pontos do Rio Grande do Norte. Posso afirmar isso tranqüilamente, pois fizemos levantamentos: a alfabetização era realizada em menos de 40 horas; era bonito ver as pessoas desarnarem as letras, construírem as palavras. Eu me encarregava de trabalhar as questões políticas que poderiam ser discutidas com as palavras-chave; montava uma espécie de referência a ser utilizada pelo monitor, se é que estou dizendo o nome certo.

Fiz questão de escrever essas lembranças, sem consultar a nada ou a qualquer pessoa. Eu as desejo brutas. É por isso que fico dizendo o tempo todo: se eu não estou enganado, é possível... Pois bem, parece que existia, institucionalizado ou não, um tal pacto operário-estudantil-camponês. Ele se declarava contra a experiência e lançava um decreto: quem trabalhasse com a Usaid era vendido ao imperialismo ianque. Marcos Guerra deixou a UEE. O estigma foi lançado pelo Partidão e por setores mais à esquerda da AP.

Falar da AP, como estou fazendo, dá a imprecisão de que vivíamos uma organização. Não era assim. Sem dúvida, havia um grupo, mas sem 
grandes formalizações, composto, sobretudo, de pessoas da JUC. Arrisco-me a dizer que a AP era mais objeto de nossa invenção do que propriamente de revolução: o carro chefe do que poderia ser chamado de esquerda era, ainda, a JUC, com a qual eu tinha ligações, embora não pertencesse e pertencesse ao mesmo tempo, o que parece uma contradição mas perfeitamente cabível àquela época. Aliás, parte do clero me gozava, chamando-me de ateu clerical e eu bem que merecia.

Todo esse besteirol começou a me chatear e hoje eu penso que jamais tive uma consciência, digamos assim, revolucionária, militante, combatente. Por bom tempo acompanhei a alfabetização pelo estado, mas guardo especial lembrança - não sei a razão - dos trabalhos em Mossoró; quando penso no MEB, a lembrança leva de imediato para Ceará-Mirim e também não sei a razão. Bom, o fato é que qualquer coisa me levaria a sair; eu andava, sem saber, procurando um pretexto; qualquer um era suficiente e apareceram dois: a vontade de casar e um boato. Disseram que um camarada da AP andava falando que eu era vendido ao imperialismo ianque. Isso era um pesado desaforo. Eu, que precisava de uma gota, tinha duas e decidi sair. Meu pai, que morria de medo do que eu andava fazendo exultou e mergulhei em direção a Maceió. Durante um bom tempo, fiquei na moita; depois, estava pondo as mangas de fora.

Um dia ouvi, pelo rádio, o que se falava sobre o comício da Central. Tive a sensação de que alguma coisa em breve iria acontecer. Nesse contexto, tive dois lances de sorte: o primeiro foi não ter ido para Sergipe participar da montagem da experiência de alfabetização acompanhando a mesma equipe com que trabalhava em Maceió; o segundo foi não ter aceito ir para Brasília na montagem do Ano da Alfabetização do Governo Jango. Quando se deu o estouro, o pessoal voltou para Natal e foi preso na estrada: Caruaru. Eu nunca entendi direito o lance dessa prisão. Já havia decidido ficar em Maceió e o negócio era ganhar dinheiro e casar; por isso, não aceitei sair.

Em Natal, meu pai queimou o que eu tinha; minha mãe vivia impressionada com umas espingardas debaixo de minha cama. Passava caminhão de soldados pela rua, ela quase batia as botas e um dia, coitada, um deles inventou de quebrar na porta lá de casa. Segundo me disseram, boatos circularam: eu havia sido preso, eu havia sido morto numa guerrilha no Paraná... Eu estava morrendo, mas era de medo. Sabia que muitos de meus amigos haviam sido presos e então liguei para um irmão de D. Eugênio: ele deveria perguntar se eu poderia ir para Natal. Ney telefona e me diz para encontrá-lo no aeroporto do Recife. Chegou, conversamos, eu estava sendo aconselhado a não botar a cabeça de fora pelo me- 
nos durante uns seis meses; mesmo depois da quarentena, se eu desejasse ir a Natal, deveria consultar primeiro. D. Eugênio havia conversado com o general Murici e havia assumido a responsabilidade comigo (minto, eu soube disso por ele depois). Foi extremamente generoso, pois era impossível que não soubesse do que andava acontecendo, do que andei fazendo.

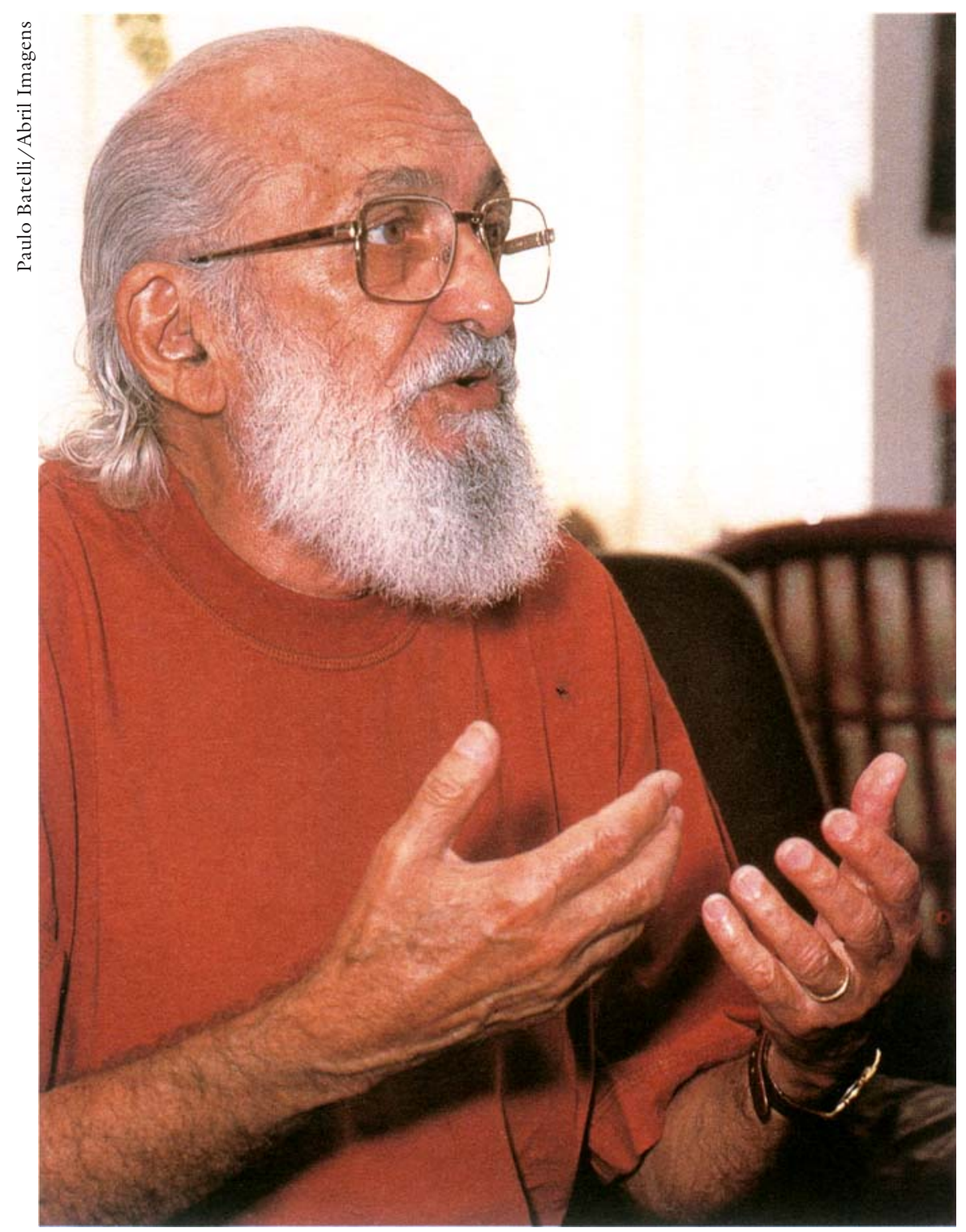

Paulo Freire

Mesmo antes de tudo isso, eu sempre argumentava que D. Eugênio não era aquele direitista de quem se falava. Comigo, pessoalmente, sempre foi um homem aberto e leal. Sei que isso não é argumento político, mas vejamos o seguinte: eu fui um de muitos que foi salvo da cadeia por 
ele; sei de casos contados por ele, inclusive na presença de um de meus irmãos, que é o Marco Antônio (Fullbright$B S B)$ quando estivemos com ele, certa feita, em Salvador. Nunca conversei demoradamente com D. Eugênio sobre 1964 e não sei efetivamente $o$ que ele pensava. Admito que aceitou 1964 como marco contra o comunismo. Tenho certeza apenas de um fato: jamais, em tempo algum, concordaria com tortura, deboche contra as pessoas, ilegalidades. Ele não pode ser considerado como um homem de 1964; ao contrário, acredito que 1964 o tomou em suas malhas, quando o vento soprava a invenção do diabo comunista sobre a Igreja.

Alguns interesses dentro da Igreja desejaram lançá-lo contra D. Helder. Eram amigos e se respeitavam, cada qual no seu cada qual. Disso D. Eugênio deu provas

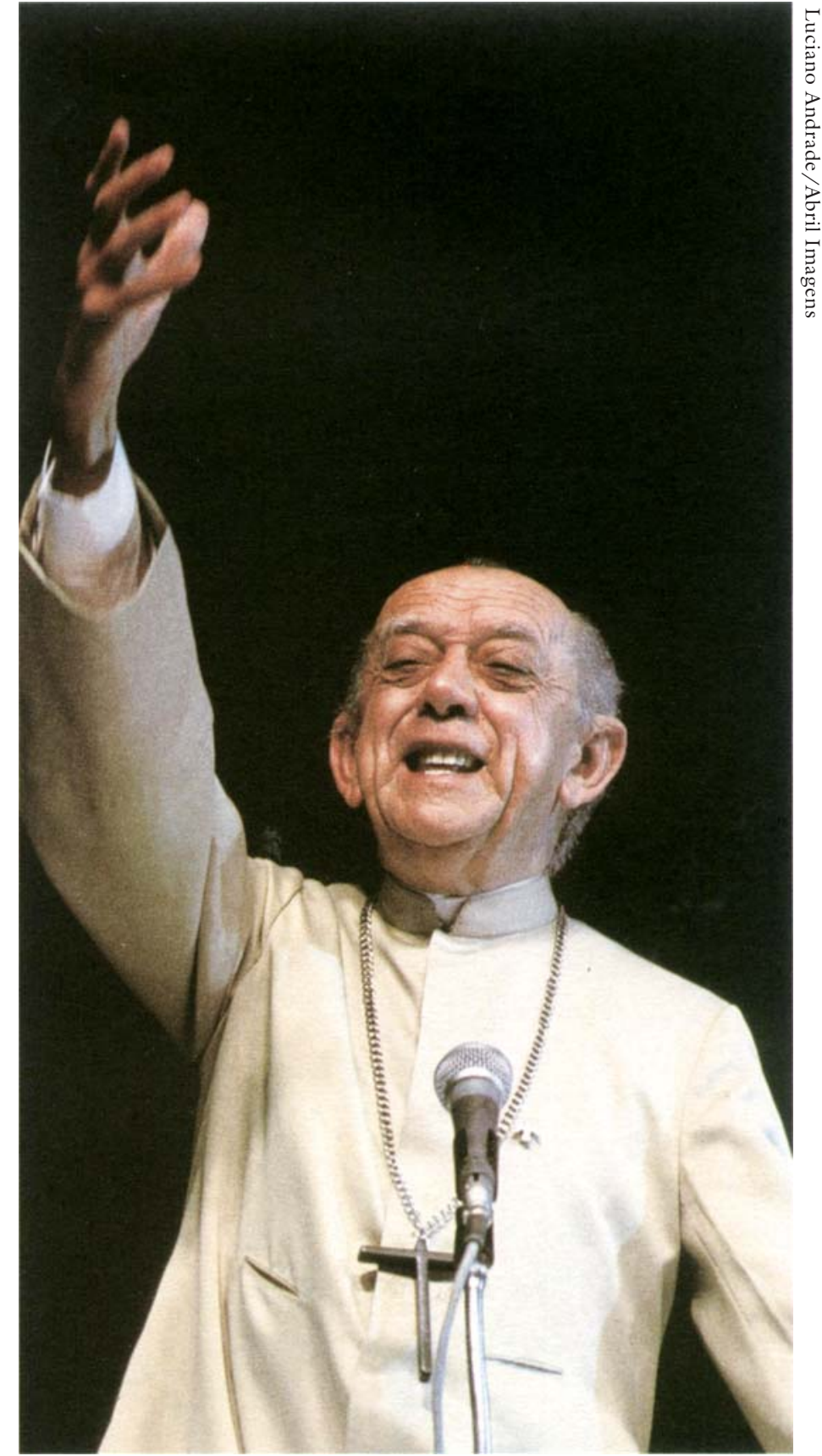

Dom Helder Câmara quando a pressão contra D. Helder estava a todo vapor no Recife. Aliás, quando do recente falecimento de D. Helder, ele esteve no Recife e celebrou missa. Lembro de algo que me disse certa feita e parece que em Salvador: havia conquistado uma posição e dela poderia fazer muita coisa. Jamais gostaria de deixar uma falsa impressão no seio dessas lembranças. Não estou dizendo que D. Eugênio era um homem infalível; pelo 
contrário, errava muito - no meu modo de ver as coisas - mas errava com reta intenção e isso é raro, extremamente raro. Pode parecer um moralismo pequeno-burguês; talvez seja. E o que sou?

Sei apenas que, apesar das discordâncias radicais, lhe quero bem e é uma das poucas pessoas que, nesse olhar para o que se foi, recupera esse carinho pessoal, essa coisa que a gente tem por quem gosta. Jamais a discordância colocou de lado este fato: gosto dele. Concordar, são outros quinhentos.

Luiz Sávio de Almeida, doutor em História pela UFPE, é professor adjunto da Universidade Federal de Alagoas, no Departamento de Ciências Sociais. Foi integrante do Setor de Sindicalização Rural do Serviço de Assistência Rural da Diocese de Natal, do Movimento de Educação de Base (Natal) e da Equipe Paulo Freire, Secretaria de Educação do Rio Grande do Norte.

Este texto é parte de um livro de memórias do autor que tem o mesmo título. 